REVIEW ARTICLE

\title{
STRESS-HOST-PARASITE INTERACTIONS: A VICIOUS TRIANGLE?
}

\author{
Beldomenico $\mathrm{PM}^{1^{*}}$, Begon $\mathrm{M}^{2}$ \\ 1 Laboratorio de Ecología de Enfermedades, Instituto de Ciencias Veterinarias del Litoral, Universidad Nacional del \\ Litoral - Consejo Nacional de Investigaciones Científicas y Técnicas (UNL-CONICET), Argentina \\ 2 Institute of Integrative Biology, University of Liverpool, United Kingdom
}

* Correspondence: PM Beldomenico. Laboratorio de Ecología de Enfermedades. Instituto de Ciencias Veterinarias del Litoral (ICIVET Litoral), Universidad Nacional del Litoral - Consejo Nacional de Investigaciones Científicas y Técnicas (UNL-CONICET). RP Kreder 2805, 3080 Esperanza, Santa Fe, Argentina. E-mail: pbeldome@fcv.unl.edu.ar

Recibido: 1 Diciembre 2015. Aceptado: 27 Enero 2016. Disponible en línea: 15 Febrero 2016.

Editor: R. Sobrero.

\begin{abstract}
SUMMARY. The potential for synergy between host physiological condition and infection has recently been recognised. Here we review the evidence to support the idea that stress may play a key role in the interplay between host and parasite, integrating a threeway circular synergistic interaction between stressors, infections and host response: chronic stress can elicit responses that impoverish the host's physiological condition (including its immune function), which predisposes to infection, which results in more stress, and so on. We argue that this introduces additional explanatory power to previous ideas posited by the authors, by including stress as a third interacting factor that intervenes in the synergy between condition and infection. This in turn, may have important implications. In nature, evolutionary forces appear to select against stress-related disease or exacerbated parasite virulence. Nonetheless, under certain circumstances, parasites and (other) stressors interact generating a vicious spiral that may affect host fitness and survival. At high host densities, this becomes a mechanism of population regulation. Also, anthropogenic stressors may cause this mechanism to misfire, with significant implications for biological conservation and public health.
\end{abstract}

RESUMEN. El potencial sinergismo entre la condición fisiológica del hospedador y la infección ha sido recientemente reconocido. Aquí revisamos la evidencia que da sustento a la noción que el estrés puede jugar un papel clave en la interacción entre el hospedador y el parásito, integrando una interacción circular sinérgica de tres vías que comprende al factor estresante, las infecciones y la respuesta del hospedador: el estrés crónico desencadena respuestas que empobrecen la condición fisiológica del hospedador (incluyendo su función inmune), lo cual predispone a infecciones, lo cual resulta en más estrés, y así sucesivamente. Sostenemos que esta noción introduce capacidad adicional para explicar las ideas previas propuestas por los autores, mediante la incorporación del estrés como un tercer factor interactuante que interviene en el sinergismo entre condición e infección. A su vez, esto puede tener importantes implicancias. En la naturaleza, fuerzas evolutivas parecen remover a enfermedades relacionadas al estrés o a la virulencia exacerbada. No obstante, bajo ciertas circunstancias, los parásitos y (otros) factores estresantes interactúan generando círculos viciosos que pueden afectar la sobrevida del hospedador. A altas densidades, este se vuelve un mecanismo de regulación poblacional. Asimismo, factores estresantes antropogénicos pueden causar que este mecanismo se dispare en falso, con implicancias significativas paraa la conservación de la biodiversidad y la salud pública.

Key words: stress-dependent prophylaxis, disease ecology, ecoimmunology, wildlife health

Palabras clave: profilaxis dependiente del estrés, ecología de enfermedades, ecoinmunología, salud de la fauna

\section{Introduction}

The concept of a vicious circle linking infection and host physiological condition elaborated by Beldomenico and Begon (2010) - in which those in poorer condition are more susceptible to infections which lower their con-dition further, making them more vulnerable still to infection, etc. - is now widely acknowledged in the literature, with around 100 supportive citations since 2010. However, there are omissions, or unstated assumptions, in the elaboration of that concept, es-pecially in terms of mechanistic or physiological con-nections between infection and condition. In particular, the origins of initial differences in condition that might initiate the vicious circle were not explored in detail; parasites were implicitly assumed to be the sole drivers of variations in host condition; and the mechanisms by which infection may lead to greater or lesser reductions in host condition were not examined.

Here we propose that incorporating a third element, stress, and constructing a potential vicious triangle, may go at least some way towards addressing these omissions, providing a more complete picture of how infection may have strongly differential effects among individuals and among populations. 


\section{Context-dependent host-parasite inter- actions}

By definition, parasites are detrimental to host fitness. However, the outcome of host-parasite interactions appears to be largely context-dependent (Brown et al., 2003; Thomas et al., 2002; Wolinska and King, 2009). The risk and severity of an infection often reflects an interaction between the environment and factors intrinsic to the parasite and host. Optimal environmental conditions for a given parasite (e.g. the right humidity and temperature for its development) can favour its fitness, resulting in increased parasite density and infections that are more likely and more severe (e.g. Manzoli et al., 2013). Similarly, relevant life-history traits of the host, such as behaviour and immune function, are highly dependent on environmental conditions (Wolinska and King, 2009).

In particular, a modification in host behaviour in response to environmental changes may directly or indirectly determine its level of exposure to parasites. For instance, ongoing reductions in sea ice are leading walruses to become more pelagic and to prey more on seals and less on invertebrates. This, in turn, may increase the prevalence of trichinellosis in walruses (Rausch et al., 2007; Utaaker and Robertson, 2015). A host's ability to counter infections is also influenced by environmental conditions, and therefore its proneness to infection may vary greatly throughout the course of its life (Lange et al., 2014; Lochmiller, 1996). For example, after periods of high field vole (Microtus agrestis) population density, food shortage compromises the voles' physiological condition (Beldomenico et al., 2008b; Huitu et al., 2007). Physiological systems are interconnected in a network of regulatory relationships that mediate homeostasis and thus organismal performance, including its ability to resist or tolerate infections (Martin et al., 2015). Thus, field voles in poor physiological condition (lower red blood cell counts and body condition) are substantially more likely to become infected with cowpox virus than individuals in good condition (Beldomenico et al., 2009b). Moreover, voles with low lymphocyte counts, an indication of poor immunological investment, are much more prone to develop high intensities of infection with the protozoan Trypanosoma microti than voles with normal lymphocyte levels (Beldomenico et al., 2009a).

The physiological condition of an animal, and hence its ability to cope with infection, may become impoverished as a result of physiological and behavioural responses to demands in its environment. These responses are likely to have evolved to enhance the likelihood of the animal maintaining organismal stability in the face of environmental change, and their cumulative cost to the animal is commonly referred to as 'stress' (Mc-Ewen, 1998). Nowadays, stress constitutes a well-developed line of research in the biomedical sciences. In the following sections we examine how stress influences host-parasite interac-tions in wildlife populations, particularly in the context of the synergy between condition and infection.

\section{Stress in nature}

The concept of stress has been used in several scientific disciplines, but often with ambiguity and lack of consistency. Hence, with the aim of avoiding possible misconceptions and confusions, we deal first with the stress concept itself, mainly focusing on its application in the context of wildlife populations.

\section{Defining stress (in a biomedical context)}

In 1936, Hans Selye described a syndrome that followed exposure to diverse injuring agents and was charac-terized by alarm, resistance and exhaustion (Selye, 1936). He named this phenomenon the 'General Adaptation Syndrome', but he conveniently used the term 'stress' to describe its manifestations, and defined it as 'the non-specific response of the body to any demand' (Selye, 1975). Work that followed recognised that the route to stress consists of three elements: 1) the exposure to a condition or stimulus (i.e. a 'stressor'), 2) the perception and processing of that exposure, and 3 ) the behavioural and physiological output (i.e. the 'stress response') (Levine and Ursin, 1991). Where the stress response appears to be demonstrably beneficial in ameliorating, perhaps entirely, the effects of the stressor, then this may be described as 'eustress'; whereas the term 'distress' describes the state of an organism unable to adapt fully to one or more stressors and thus having a compromised wellbeing. Of course, even with apparent eustress, an organism may be paying a hidden price for the amelioration, for example in energetic terms.

In biomedical research, it is of interest to differentiate successful physiological and behavioural responses to noxious stimulation (eustress) from demands that exceed the regulatory capacity of organisms (distress). But it has further been suggested that the term stress should be reserved for cases where there is a cognitive perception of conditions that are unpredictable (not accompanied by an anticipatory response) and uncontrollable (followed by delayed recovery or death) (Koolhaas et al., 2011). Thus, stress is equated with 'distress', as defined above, and 'eustress' is not used at all. Following this line of reasoning, stress is defined in a biomedical context as "the physiological and behavioural response to unpredictable and/or uncon- 
trollable demands that exceed the regulatory capacity of an organism" (Koolhaas et al., 2011).

\section{Mechanisms of the stress response}

In vertebrates, although it has been shown that different stressors activate different stress bio-markers and different regions of the brain (Pacak and Palkovits, 2001), it is accepted that for most stressors there is at least some overlap in response (Fink, 2009; Wingfield, 2013a). This consensus response to stressors consists of a cascade of adaptive events initiated when a stressor is perceived, sensorially, by the animal. These events include, on the one hand, behavioural reactions, and on the other, activation of the sympatho-adreno-medullary (SAM) and the hypothalamus-pituitary-adrenal/inter-renal (HPA or HPI) systems. The physiological changes associated with the acute response to stress result in preparedness to flee or fight. If the stressor persists, however, glucocorticoid production reorganizes the physiological economy, inducing catabolism to supply the body with energy (Tempel and Leibowitz, 1994) and restricting the immune system, thus preventing deleterious effects of inflammatory factors (Munck et al., 1984). Continued exposure to the damaging agent may result in habituation and a gradual decline of response (Grissom and Bhatnagar, 2009), or in exhaustion and eventually death (Fink, 2009).

\section{Defining stress in natural populations}

Physiological ecologists have generally adopted the definition used in medical research to study stress in nature, but, as recently argued by Boonstra (2013), this influence has sometimes hindered proper acknowledgement of the ecological and evolutionary context in which wild animals live. In our opinion, the main conflicts lie in the concepts of 'predictability' and 'controllability' as applied to natural systems. When the stress response is preceded by an anticipatory response, the stimulus that caused it is classified as 'predictable'. This ability to predict demands being made on an animal allows a preparedness that improves the chances of success, and therefore predictable aversive stimuli are less likely to result in pathological consequences than unpredictable ones. In biomedical research, the 'predictability' of a stressor is often associated with anticipation via cognitive processing that follows repeated exposures to the same stimulus (lifecourse predictability) (Koolhaas et al., 2011), but physiological ecologists also apply the term 'predictable' to environmental challenges that have a regular occurrence in the life history of a species (ancestral predictability) (McEwen and Wingfield, 2003; Wingfield, 2013b), even if individuals experience this challenge only once in their lifetimes (as elaborated below in the salmon example). Challenging demands that are a predicable part of the life cycle of a species may often be accompanied by a series of anticipatory adjustments that aid in the success of the stress response, classifying that response as 'eustress'; but those demands may sometimes be so severe that they lead to 'distress' (i.e. true stress). For example, salmon must endure a long migration upriver to spawn (a predictable stressor). This is accompanied by a rise in glucocorticoids, anorexia and atrophy of the digestive tract (Carruth et al., 2014), and after the eggs are fertilized, the salmon's deteriorated condition is incompatible with survival. However, this sacrifice will have ensured the salmon's reproductive success. Although they both generate an anticipatory response, ancestral and life-course predictabilities have different origins and use different neuroendocrine pathways. Hence, it is important that they are properly distinguished and acknowledged. In this review, uses of 'predictable' or 'unpredictable' refer to ancestral predictabilities.

Turning to controllability, stressors that result in only partial recovery or a failure to recover following the neuroendocrine reaction are known as 'uncontrollable' (Koolhaas et al., 2011). As argued above, unpredictable stressors are also more likely to be uncontrollable. However, within a natural population, predictable stressors may also be uncontrollable, especially as an aversive stimulus may be perceived as only a mild demand with minor consequences by a proportion of the individuals, but as a severe stressor by others. This distribution of perceptions may depend not only on the type of stressor (e.g. predictable or unpredictable), but on differences in exposure intensities, frequencies and durations, and heterogeneities in host genotypes/phenotypes, as well as interactions with other stressors. For example, every spring, populations of some rodent species face predictable demands related to the need to grow and develop their reproductive system during a food shortage period, and they undergo a number of seasonal adjustments in their physiology to overcome them (Beldomenico et al., 2008b), but these stressors still have the potential to affect life courses and population dynamics. In fact, the combination of these demands and parasite infections are the main cause of seasonal population crashes (Pedersen and Greives, 2008), known as 'spring declines' (Krebs and Boonstra, 1978). Sometimes, these predictable spring stressors are uncontrollable for a large proportion of the individuals in a population, because they are stronger than usual and/or the animals are in poor physiological condition, which results in years of drastic population crashes. In other years, the stressors may be perceived as mild, being controllable for most individuals and leading to virtually no spring decline.

Hence, here, 'stress' will be used to describe the interaction between stressors and stress response that exceeds the regulatory capacity of an organism, but which do not necessarily result from exposure to 
stimuli deemed a priori to be unpredictable and/or uncontrollable.

\section{The evolution of the stress response}

Although in humans and domestic animals stress is associated with disease, the stress response may also be seen as a useful adaptive mechanism. It is a consequence of evolutionary forces acting on individuals' fitness (reproduction and survival) through appropriate allostasis (Korte et al., 2005). Allostatic adjustments have obvious advantages, but they may be physiologically costly (McEwen, 2002). Therefore, if an aversive stimulus is insignificant to fitness, individuals would do best to ignore it and invest instead in more necessary physiological processes (McNamara and Buchanan, 2005). In the course of each species' evolution, therefore, the stress response has inevitably been shaped by species-specific tradeoffs that determined a balance between costs and benefits when facing predictable (e.g. seasonal migration) or unpredictable challenging events (e.g. storms). Thus, although two phylogenetically related vertebrate species may share a common set of stress response mechanisms and mediators, they may still have contrasting responses to stressors, which largely stem from differences in their life histories (Reeder and Kramer, 2005). Boonstra and collaborators (2000; 2001) provide a good example contrasting American red squirrels (Tamiasciurus hudsonicus) and arctic ground squirrels (Spermophilus parryii). These species may be phylogenetically related (i.e. they are both Sciuridae), but they have very different life histories and occupy different niches. The HPA system of male arctic ground squirrels is much more sensitive than that of male American red squirrels (Boonstra et al., 2000), so that the functions associated with the HPA axis are compromised when male Arctic ground squirrels breed, but not when American red squirrel males do so. The red squirrels have evolved with a stable social system based on long-lived animals with individual territories needed to deal with unpredictable winter food supplies, but the ground squirrels escape the rigors of winter by hibernation and their HPA axis has evolved in short-lived males in the context of intense intra-sexual competition (Boonstra et al., 2000). In such circumstances, it may pay ground squirrel males to put all their resources into maximising reproduction at the expense of survival (Boonstra et al., 2001).

The evolution of the stress response may also favour contrasting stress-coping strategies among conspecifics (Koolhaas, 2008). In particular, a theoretical framework has been generated that describes the existence of two evolutionary stable strategies, with empirical support in bird and mammal species (Koolhaas, 2008; Korte et al., 2005): proactive, 'hawktype' individuals, characterised by aggressive behaviour, high risk taking and high SAM sensitivity, and passive, 'dove-type' individuals with non-aggressive and cautious behaviour, thorough exploration of the environment and high HPA sensitivity.

\section{The interaction of stress and parasitism}

In this section, we discuss the links between stress and host-parasite interactions, emphasising the reciprocal effects between them and the establishment of a circular three-way interaction between stressors, the host's physiological condition, and the infection.

\section{The side effects of stress: impact on infection risk}

The effects of stress include alterations in processes that influence the host-parasite interaction directly: host behaviour and immune function. While behaviour may mainly affect the initial step of the host-parasite interaction, i.e. exposure, the immune function modulates the remaining steps: parasite establishment, development, and proliferation or sexual reproduction.

Changes in behaviour in response to a stressor may result in more or less exposure to parasites. For example, in many wildlife species, glucocorticoids promote foraging activity (e.g. Belthoff and Dufty jr, 1998; Crossin et al., 2012). This behavioural decision may be appropriate where it is necessary to increase food intake, but it carries the consequence, potentially, of greater exposure to trophically transmitted parasites. On the other hand, predatory stress can reduce foraging activity, thus reducing infection risk (e.g. Giles, 2006). Further, many parasites have been found to manipulate host behaviour to enhance transmission (Lafferty and Shaw, 2013). There appears, therefore, to be the opportunity for the development of interactions between stress, host behaviour and infection, but the influence of stress on this three-way interaction seems not yet to have been explored.

Much more work has been devoted to investigate the role of stress on host immunity and susceptibility to infection. It is well known that stress hormones modulate the immune system of animals, both in vertebrates and invertebrates (Adamo, 2008). While basal glucocorticoid levels appear to be necessary for immune activation, it is generally accepted that most glucocorticoid actions on immune and inflammatory responses are suppressive (Sapolsky et al., 2000). However, the effect of stress on the immune response depends largely on the duration of exposure to stresssors. In response to stressors lasting minutes to days, immune function (particularly via innate inflammatory processes) is enhanced, whereas if the stressors persist for longer periods the immune system is generally suppressed (Martin, 2009). Early enhancement of the innate defences represents an adaptation to endure or recover from stressors. If the 
stressor persists, the immune suppression that follows has been variously interpreted as the result of a tradeoff in which resources are redirected to activities that are a priority for survival (Sapolsky et al., 2000), and/or as an effort to minimise autoimmune damage (Raberg et al., 1998) or the detrimental effects of inflammatory factors (Munck et al., 1984), though it may simply reflect a failure to cope with the totality of demands (and hence be maladaptive) (McEwen and Wingfield, 2003).

Largely, studies in wildlife show that in the long term, stress-immune interactions dampen immune function. For instance, nutritional stress in wild rodents was shown to cause a reduction in spleen mass and cellularity and to decrease the numbers of antibody producing cells (Martin et al., 2008; Vestey et al., 1993). Similarly, negative social interactions in rodents are consistently associated with lower lymphocyte proliferation and decreased antibody production (Bartolomucci, 2007). One of the main stressors faced by amphibian larvae is the desiccation of the water body where they develop. A response to this stressor is accelerating development for earlier metamorphosis, which is beneficial for survival in the short term, but this trades off against time to maturity (Smith, 1987), fecundity (Howard, 1980), and also immune function (Gervasi and Foufopoulos, 2008).

\section{Are maladaptive stress responses removed by natural selection?}

In terms of evolutionary adaptation, it makes little sense for individuals under chronic stress to suppress the whole immune system, as immunity could be critical for enduring stressors (Martin, 2009). If the stress-associated reduction of the immune function had a significant negative net impact on individual fitness and ultimately population dynamics, natural selection would tend to remove this maladaptive response. For example, while house sparrows (Passer domesticus) of temperate regions undergo immunesuppression as a response to glucocorticoid surges, the immune sys-tem of sparrows that inhabit tropical areas, and that are therefore more exposed to pathogens, is insensitive to glucocorticoids, thus ensuring that individuals maintain proficient defences even during stressful times (Martin et al., 2005). Similarly, if an increased exposure to a given group of parasites caused by stress-induced changes in behaviour were of enough significance, we can expect natural selection to have found ways of minimising its consequences. In this regard, the hawk- and dove-type coping styles described above in behavioural /physiological terms are accompanied by seemingly appropriate immune responses (Koolhaas et al., 1999). Evidence from laboratory rodents suggests that the coping style extremes are characterized by an opposite balance between different $T$ helper cells mediated by a differential HPA axis reactivity (Koolhaas, 2008).
Hawks, being more aggressive and bold, are arguably more at risk of wounding and becoming infected with bacteria during fighting. Their immune system is dominated by inflammatory responses (Th1-biased). The exploratory nature of doves, by contrast, exposes them to higher risk of parasite propagule exposure. Their immune response is more anti-helminthic (Th2biased) (Korte et al., 2005; Martin, 2009).

Related to this, since the immune system consists of a complex web of interacting components (Raberg et al., 1998), and the responsiveness of each to stress varies (El-Lethey et al., 2003), we can expect any differential response to reflect the need to preserve particular components of the immune function during chronic stress. Thus, a host species whose life history is characterised by periods of greater risk of infection by part of its parasite community may have evolved a stress response that enhances the component of the immune system that controls that group of parasites. Capybaras (Hydrochoerus hydrochaeris) appear to provide an example of this (Eberhardt et al., 2013). Prolonged exposure in experiments to either restraint or food restriction resulted in increased levels of circulating eosinophils, a leukocyte associated with Th2 responses, and indeed, at the end of the experiment, stressed capybaras had much greater intensities of infection with coccidians (which require a Th1 immune response) but similar or significantly lower burdens of nematodes (which require a Th2 immune response). Capybaras are grass feeders (Moreira et al., 2013), and so when there is little grass left (nutritional stress) they might feed close to the ground and thus become more prone to ingesting parasite propagules (Figure 1). It is well known, certainly, that low grazing heights contribute to increased parasite intake in livestock, as helminth immature stages concentrate in the lower portion of the pasture (Sykes, 1987). Increased eosinophils in stressed capybaras may therefore reflect an enhanced Th2 immune response in these individuals, and a preparedness in anticipation of greater risk of helminth exposure: a 'stress-dependent prophylaxis', or a condition-dependent change of their defence strategy against helminths, shifting from tolerance to resistance.

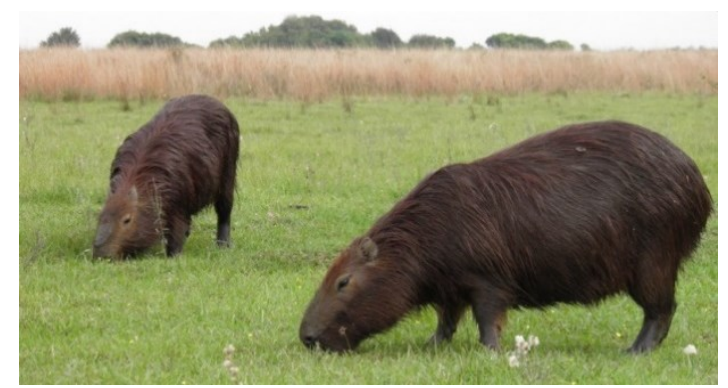

Figure 1. The way of foraging of capybaras exposes them to the ingestion of parasite eggs or larvae, especially when there is food shortage, as they need to graze closer to the ground, where parasite propagule density is highest. (Photo credit: Ayelen T. Eberhardt). 


\section{Reciprocal effects between stress and parasitism}

It has been documented in a variety of host-parasite systems that individuals in poor physiological condition are more likely to become infected and these infections are more likely to be severe. Infection, in turn, further reduces an individual's condition, which results in proneness to new infections, and so on, causing a vicious spiral that may eventually lead to death (reviewed in Beldomenico and Begon, 2010; Blanchet et al., 2009). Stress and parasitism have similar characteristics of reciprocity. As elaborated above, chronic stress may elicit responses that dampen the immune system, increasing the risk and severity of infections, while parasites act themselves as chronic stressors. In vertebrates, infection triggers the production of cytokines that activate the HPA system (Turnbull and Rivier, 1999). Experiments in diverse taxa have demonstrated that infection can cause an increase in stress hormones (e.g., St Juliana et al., 2014; Sures et al., 2001). Hence, these reciprocal effects can lead to a circular three-way interaction, complementing the vicious spiral and improving our mechanistic understanding of it: the stress response impoverishes the host's physiological condition, affectting its defences, which predisposes to infection, which results in more stress, and so on (Figure 2).

One implication of this is that parasite infection can be both cause and consequence of the stress response. A number of cross-sectional studies in different taxa have shown positive correlations between parasite load and stress hormones (e.g. Brown and Fuller, 2006; Raouf et al., 2006). However, for the reasons explained, it is not possible to establish from these studies whether parasites caused the stress hormones to rise, or stress facilitated parasite infection, or the association was the result of reciprocal effects and vicious circles. Hence, the establishment of causeeffect interactions between stress and parasitism requires longitudinal and experimental approaches.

The limited literature from longitudinal and experimental studies supports the notion of synergy between stress and parasitism. Pioneer work conducted by Ould and Welch (1980) showed that ducks stressed experimentally (either by crowding or by glucocorticoid injection) and infected by the nematode, Echinuria uncinata, showed signs of a depressed immune func-tion (involution of the bursae of Fabricius and thymus glands, and less eosinophils infiltrating granulomas), which in turn resulted in greater nematode numbers and sizes. That experiment did not provide evidence of synergism (the detailed time course of events was not followed), but it did demonstrate part of the underlying suite of mechanisms postulated above.

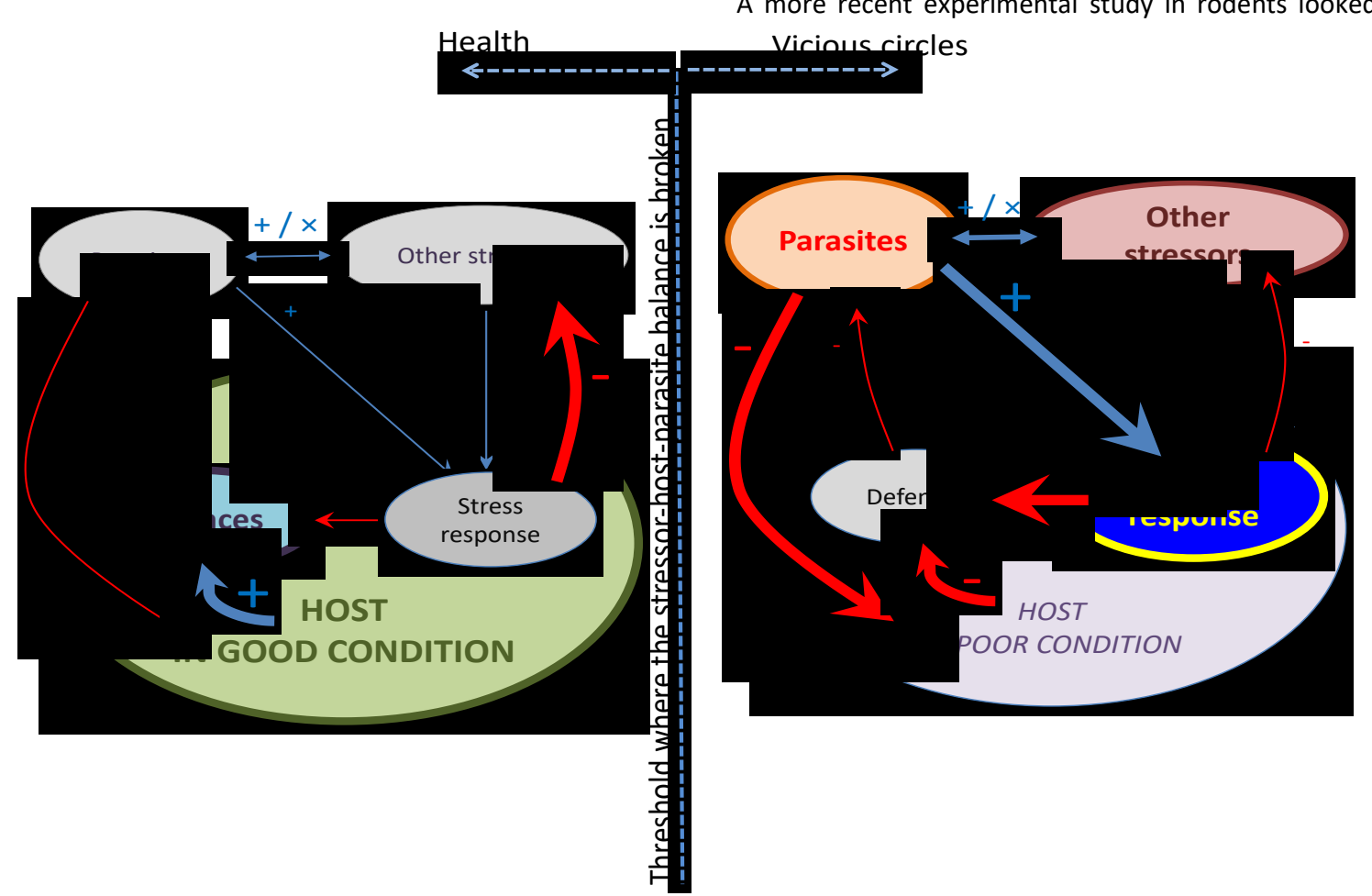

Figure 2. Balanced and unbalanced stressor-host-parasite interactions. Each diagram represents an individual. The one on the left, healthy, the one on the right, one with its regulatory capacity overwhelmed by stressors. Diagram are daily exposed to different interacting stressors (including parasites), which are overcome by their physiological regulatory network (including the stress response and the immune function), resulting in a stress-host-parasite interaction. When parasite burdens and other stressors are at low to moderate levels and hosts are in good physiological condition there is a balance in the stress-host-parasite interaction. A significant disruption in one or more of the components of this interaction might break this balance, triggering a vicious circle. Infection affects the physiological condition of individuals, including its barriers and defences against infection. Infection also dampens immunity by eliciting a stress response. The stress response to other chronic stressors also affects the immune function, therefore making individuals more susceptible to infection. Parasites may interact additively or synergistically with other stressors, fuelling the cycle. Size of arrows depict the magnitude of the effect. Blue arrows indicate positive and red ones negative effects. 
thoroughly into different key components of the stress-host-parasite interaction and their consequences. Pedersen and Greives (2008) conducted a community trial where replicated populations of white-footed mice (Peromyscus leucopus) and deer mice (Peromyscus maniculatus) received either food supplementation, or a long-lasting broad-spectrum anti-parasitic drug, or both treatments, or neither. Immediately before the 'spring decline', faecal glucocorticoid levels were significantly reduced in populations receiving both food supplementation and removal of parasites. Those populations did not decline, while those in other treatments did. Antihelminthic drugs or food supplementation had a significant effect on survival when administered alone, but both together had an impact much greater than sum of each individual effect. This suggests strongly that a vicious circle is in operation: that the combination of food shortage and parasite infection acts synergistically to cause an impact on host fitness and population dynamics via a mechanism that involves the stress response, as evidenced by the faecal glucocorticoid levels.

Recent studies in invertebrates provide further evidence of the synergistic interaction between stress and parasitism and its impact on host population dynamics. In the bivalve mollusc, Mesodesma donacium, it was found that the combined effect of environmental stress and parasite load (especially of the spionid annelid Polydora bioccipitalis) explained population crashes (Riascos et al., 2011). In particular, in this work it was observed that population crashes after strong changes in beach condition. During those population crashes, clams that died were generally infested by $P$. bioccipitalis, whereas surviving clams were almost exclusively non-infested. Studying bees, Nazzi et al. (2012) integrated results from empirical and theoretical research and found that bee colony collapses are caused by interacting stress factors that affect the balance between pathogens and host immunity. Otherwise silent infections with 'Deformed wing virus' (DWV) become uncontrollable and kill the bees when accompanied by infection with the mite Varroa destructor, the stress response and a suppression of the immune system.

\section{Stress-host-parasite interactions and host population dynamics}

Although it has recently been argued that there is no evidence that chronic stress results in an impact on wildlife population dynamics via pathological effects on individual fitness (Boonstra, 2013), the vicious circles posited here, resulting from the stress-hostparasite three-way interaction, invite a reconsideration of that denial. A stressor might not in itself result in a substantial impact on wildlife population dynamics, and the evolutionary reasons for that have been elaborated above, but it may affect population dynamics when acting in combination with parasite infections. Similarly, endemic parasites may only contribute to wildlife population declines given the necessary stressful context (like in the DWV example above). Thus, a wild animal's health could be defined as its state of balance between the stressors (including parasites) and the physiological regulatory network of the host (including the stress response and the immune function). Synthetically, health is the balance in the stress-host-parasite interaction (Figure 2). Healthy individuals are generally resilient to stressors, have relatively low parasite burdens and are in good physiological condition. Beyond a threshold in the levels of stressor exposure, parasite density and/or deterioration in host's condition, the vicious circle is triggered and the balance is broken. One stressor alone (e.g. infection by a parasite) might be overcome with little effort, but, by means of this mechanism, the interaction of several stressors could be overwhelming. In a wildlife population, individuals would then be polarised into the 'healthy' and the 'ill', but the latter might be less visible as they would not survive for long. However, when 'ill' individuals are particularly visible and abundant (or somehow detected) they might be announcing a drastic population collapse (e.g. Alford et al., 2007; Batzli and Pitelka, 1971; Gordon et al., 1988; Gulland, 1992; Yang et al., 2007).

In nature, this three-way interaction could become a mechanism of population regulation, as it may be triggered when host abundances have been high. High population density is associated with increased glucocorticoid secretion in a wide range of taxa, including mammals, birds, fish and reptiles (Creel et al., 2013). At high host densities, two stressors commonly faced simultaneously by many wildlife species are social conflict (e.g. territoriality, dominance) and food shortage. These stressors may interact in an additive or synergistic way to increase infection risk. For example, it has been observed that food restriction in rats affects their social behaviour (Govic et al., 2009). This inter-action might have implications for infection dynamics, as food limitation increases intra-specific interactions and environmental exploration, thus making parasite exposure more likely. Also, the low food availability that follows high population densities results in chronic stress and deteriorated condition (Huitu et al., 2007), which contributes to increased infection risk and elevated parasite output. The results are progressively deteriorated immune systems faced with increasingly high parasite exposures. So, endemic parasites may be only rarely pathogenic, but through this mechanism they could cause substantial impact on the health of hosts in circumstances of chronic stress. This stress-dependent vulnerability of the host may be the mechanism by which parasites exert a control on host populations, as when their densities have been high, hosts tend to be stressed and in poor condition, 
and parasite exposure is augmented (Figure 3). Once densities are lowered, stressors subside, parasite exposure declines and hosts improve their condition.

This hypothesis needs to be tested for different systems, requiring research that concomitantly examines the relationship between parasites, host physiology (including stress response and immune function) and population dynamics. Such studies have been rare, but the few that exist support the link between stress, infection and population regulation. There are examples from rodents, Soay sheep, and primates. In the experiment conducted by Pedersen and Greives (2008), described above, seasonal rodent population crashes were suppressed only when the combined action of two stressors, food limitation and helminth infection, were removed. Similarly, a more recent experiment in voles showed that only populations with food supplementation and not exposed to the bacterium Bordetella bronchiseptica exhibited consistent positive population growth in late winter. Populations experimentally infected with $B$. bronchiseptica and/or without food supplementation declined in size (Forbes et al. 2015). Further, recent experimental evidence showed that maternal stress combined with adult stress at high densities results in negative synergistic effects on immune traits in voles, which led to higher coccidial infections (Du et al. 2015).

Soay sheep in the Saint Kilda archipelago, Scotland, experience multiannual cycles with periodic mass mortalities of up to $50 \%$ of the population (Coulson et al., 2001). The proximate cause of death has been determined to be protein-energy malnutrition associated with harsh winters (nutritional stress), but parasites have been implicated as a key contributing factor (Grenfell et al., 1995). An experimental study showed that the administration of antihelminthic drugs at the time of the population crash considerably reduced mortality (Gulland et al., 1993), which supported the link between parasites and death. Environmental stress appears to mediate the increase in parasite burdens observed in Soays, influencing survival. Sheep that experienced more stress throughout their lives had higher parasite burdens, suggesting a cumulative impact of stress on immune function (Hayward et al., 2009). Furthermore, recent data suggests that sheep that survive the stressful periods may have invested more in defences against helminths (Nussey et al., 2014).

The population abundance of red colobus (Piliocolobus tephrosceles) is also influenced by synergistic effects of food availability and parasite infection (Chapman et al., 2006a). A decline in food availability had a direct negative impact on colobus population abundance, and an indirect effect via parasite infections. A study conducted across the Atlantic Ocean shed similar results. Six black howler (Alouatta pigra) groups from southern Belize were followed for a 5-year period, and data on faecal glucocorticoids, parasite infections and diet were collected (Behie and Pavelka, 2013). Monkey population density was positively correlated with fruit consumption, but negatively associated with multispecies parasite infections and cortisol levels. The latter were high in individuals with low food consumption and high parasite burdens. These results led the authors to conclude that low food availability, increased parasitism and the stress response interact to influence primate population dynamics.

\section{Anthropogenic stressors disrupting the stress-host-parasite balance}

In nature, these synergistic interactions involving natural stressors that contribute to wildlife population declines should arguably not be a threat to the conservation of those populations, even when they result in drastic population collapses. Predictable or not, the vast majority of natural stressors have been part of the natural environment throughout the evolutionary tra-

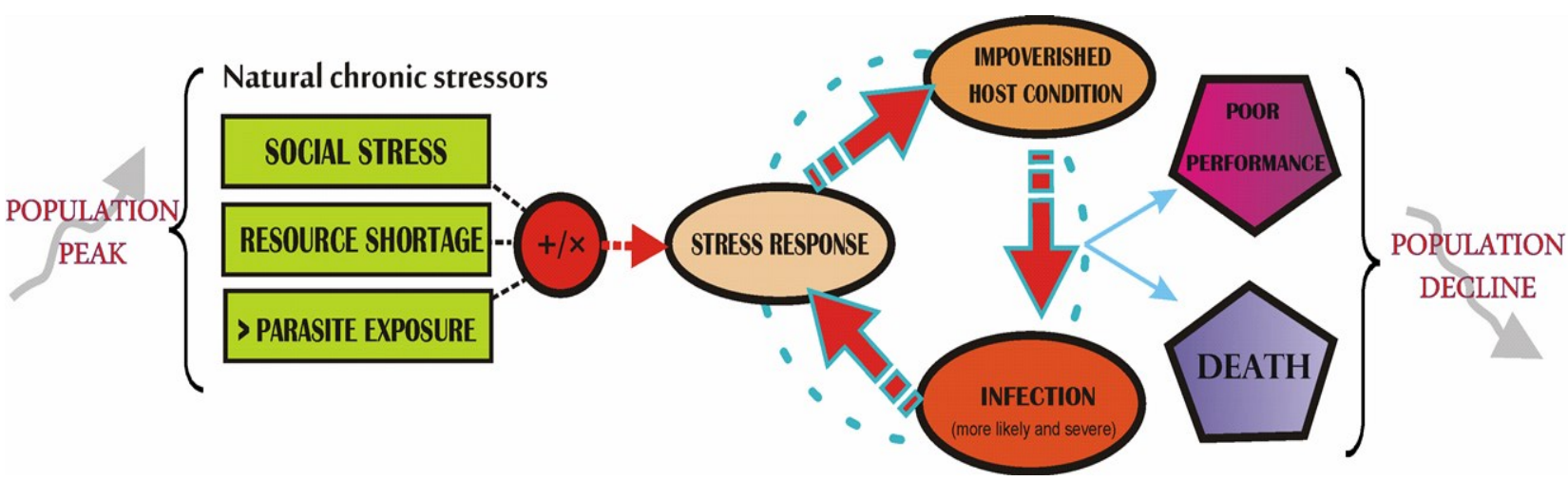

Figure 3. The hypothetical synergistic effect of stress and parasitism as a mechanism of population regulation. The stressorhost-parasite interaction as a mechanism of population regulation: Following high host population densities, chronic stressors such as resource shortage, social stress, and greater parasite exposure may interact additively or synergistically $(+/ x)$, causing a stress response which affects the condition and immunity of individual hosts. An individual with an impoverished condition is more prone to developing infections that are also more likely to be severe, which causes more stress with a resulting increasing deterioration in condition, and a vicious circle is created. At the population level, a great proportion of individuals in poor condition will cause both a large number of infections and more severe infections, resulting in pathogen exposure being greater, with a consequential reduced fitness and survival and thus reduction of host population abundance. The same mechanism may misfire when anthropogenic stressors interact with natural stressors, disturbing the stressor-hostparasite interaction and inducing population declines, even when their abundances are not high. 
jectory of a species, being one of the drivers of natural selection. As it is usual for some wildlife species to sporadically, or regularly, face the combined effect of these stressors (including parasites), they will have had the opportunity to evolve appropriate coping strategies that enable them to persist beyond the difficult period. This is not the case, however, for anthropogenic stressors.

Ongoing anthropogenic global change entails dramatic perturbations that act as stressors. Among the human activities that demand ecological and evolutionary adaptations are habitat degradation, pollution, irrational extraction of natural resources, species translocation (leading to invasions), and anthropogenic climate change. These anthropogenic stressors may interact with natural or other anthropogenic stressors resulting in additive or synergistic effects (Parmesan et al., 2013). For ex ample, predatory stress (exposure to predators, a natural stressor) caused an increase in the susceptibility to common pesticides (insecticides and herbicides, an anthropogenic stressor) in tadpoles of some amphibian species (Relyea, 2004). It is relevant to clarify that, in general, besides eliciting a conventional stress response, a stressor may influence other physiological processes. Consequently, the effects of a given stressor reflect those of the stress response plus other accompanying processes, which vary depending on the particular stressor. Therefore, anthropogenic stressors may disrupt the balance in stress-hostparasite interactions in more than one way. For instance, anthropogenic pollutants frequently elicit a stress response (e.g. Franceschini et al., 2008; Laws et al., 2009), but they concomitantly induce physiological disruption by means of their specific toxic effect.

Rapid human-driven change has made, relative to the evolutionary history of species, a sudden and explosive entrance. Thus, natural selection has had few generations to act upon shaping an optimal stress response. Although some natural stressors may also be sudden and uncontrollable (e.g. earthquakes, tsunamis), they are in general labile factors (i.e. they eventually subside), while anthropogenic stressors tend to be permanent and continuously growing (Wingfield, 2013a). The regulatory mechanism described above might misfire in the presence of anthropogenic stressors affecting the health of wildlife, with potentially dramatic implications for biological conservation.

This hypothesis has widespread empirical support. It has been demonstrated in many phyla that, in general, fitness and survival of organisms exposed to anthropogenic stressors is lower in infected than in uninfected individuals (reviewed in Marcogliese and Pietrock, 2011). Also, while habitat loss and fragmentation is identified as one of the main causes of extinction in terrestrial animals (Laurance et al., 2012), and while the mechanism by which drastic habitat destruction causes local extinctions is arguably obvious, more subtle disruptions in natural habitats can also affect population dynamics by interfering with the stress-host-parasite interaction. The prevalence and richness of gastrointestinal parasites is greater in redtail guenons (Cercopithecus ascanius) inhabiting disturbed habitats (logged forests), for example, than in individuals from un-disturbed forests (Gillespie et al., 2005). It has been suggested that this is linked to dietary stress resulting from logging activity (Chapman et al., 2006b).

Pollutants can exert a pathological effect on wildlife per se, but they may also interact with other stressors and parasites to impoverish animal health and increase mortality (Marcogliese and Pietrock, 2011). For insdance, glyphosate, the most widely used herbicide in the world, was found, alone, to have no impact on the survival of a fish (Galaxias anomalus) (Kelly et al., 2010). A common trematode parasite of that fish (Telogaster opisthorchis) does not affect survival either in the absence of the herbicide. However, the combined exposure to glyphosate and the parasite significantly reduced fish survival (Kelly et al., 2010). The same phenomenon, with other pesticides, was demonstrated in invertebrates (Coors and De Meester, 2008; Coors et al., 2008).

The potential conservation impact resulting from disrupted stress-host-parasite interactions may contribute to our understanding of the global amphibian crisis. Worldwide amphibian decline has been related to infection with a fungal pathogen (Batrachochytrium dendrobatidis) (Lotters et al., 2009). However, evidence indicates that this pathogen is neither a necessary nor a sufficient cause of the ongoing declines. The presence of the fungus does not always lead to frog mortality, and in declining populations where the fungus is absent, other macro- and microparasites were found at high prevalences (Di Rosa et al., 2007). It has also been reported that global warming can degrade toads' condition (Reading, 2007), that toads with less body mass (a sign of weakness) were more likely to die from $B$. dendrobatidis infection (Garner et al., 2009), and that frog population crashes due to $B$. dendrobatidis were preceded by periods of increasing stress (as evidenced by increasing limb asymmetry) (Alford et al., 2007). Two recent independent studies found new strong evidence of the link between the stress response and $B$. dendrobatidis infection. Glucocorticoid release rates were higher in wild populations of two frog species infected with $B$. dendrobatidis than in uninfected populations (Gabor et al., 2013). And an experiment conducted with another frog species under laboratory conditions com-pared $B$. dendrobatidis infected frogs with and without clinical sings of disease and found that diseased frogs had elevated baseline glucocorticoid levels and poorer body condition than those with subclinical infections (Peterson et al., 2013). Thus, as has previously been hypothesised (Beldomenico et al., 2008a; Kiesecker, 2010), the underlying cause of these declines might be a disrupted stress-host- 
parasite interaction due to anthropogenic stressors (i.e. global climate change, pollutants, land use change, etc.).

It can further be inferred that this interaction between stress and parasitism may have negative implications for public health and veterinary medicine. Although so far there is a paucity of data to support this assertion, there are several reasons to consider it highly likely, and some studies have already produced supporting evidence. For example, bats are the source of a number of emerging pathogens of animal and public health significance, Hendra virus being one of them (Plowright et al., 2015). Nutritional stress was found to be one of the main risk factors for Hendra virus infection in flying foxes (Pteropus scapulatus) (Plowright et al., 2008). The highest seroprevalences were observed when bats showed signs of nutritional stress. Further, bat populations excreting Hendra virus near the 2011 and 2013 spillover events experienced resource shortage and showed signs of nutritional stress (Plowright et al., 2015)

\section{Concluding remarks}

Understanding how host-parasite interactions vary in cases where the host is subjected to other stressors is of central importance for parasitology, epidemiology and disease ecology. The stress-host-parasite interaction implies a complex system, and, embedded in a wider web of interactions, it is not surprising that there will be exceptions to the patterns postulated here. The reciprocal effects between host condition and parasites could go in the opposite direction to the one proposed (e.g. for trophically transmitted parasites, host condition may be positively associated with infection) (Blanchet et al., 2009), and the effects of interactions between stressors can be antagonistic (Coors and De Meester, 2008). Nonetheless, the information summarised here allows us to establish and explain some dominant patterns. The exposure to natural stressors is part of the life history of wildlife species, which have evolved strategies to endure them. Therefore, in nature, the pathological consequences of stress tend to be gradually corrected by evolutionary processes. Similarly, for a given hostparasite association, selective pressures, on the host especially, will lead co-evolutionary trajectories towards moderate to low virulence levels (Leggett et al., 2013). However, under certain circumstances, parasites and (other) stressors interact generating a synergistic effect that results in pathological effects and impact on host fitness and survival. When this occurs at high host densities, it becomes an effective mechanism of population control. When it is triggered by anthropogenic stressors, it could have negative implications for biological conservation, wildlife management, animal hus-bandry and public health.
Studies of the stress-host-parasite interactions are still in their infancy, and there is need to aim research initiatives in several directions, integrating the emerging disciplines of disease ecology, eco-immunology and physiological ecology. This knowledge will improve our capacity to better understand the influence of anthropogenic stressors on the epidemiology of emerging or re-emerging infectious diseases, predict and reduce its conservation impact, and also enable an improved understanding of infection dynamics and the natural history of wildlife species more generally.

\section{References}

Adamo S. 2008. Norepinephrine and octopamine: linking stress and immune function across phyla. Invertebrate Survival Journal, 5, 12-19.

Alford RA, Bradfield KS, Richards SJ. 2007. Ecology: global warming and amphibian losses. Nature 447, E3-E4.

Bartolomucci A. 2007. Social stress, immune functions and disease in rodents. Frontiers in Neuroendo-crinology 28, 28-49.

Batzli G, Pitelka F. 1971. Condition and Diet of Cycling Populations of the California Vole, Microtus californicus. Journal of Mammalogy 52, 141-163.

Behie A, Pavelka M. 2013. Interacting roles of diet, cortisol levels, and parasites in determining population density of Belizean howler monkeys in a hurricane damaged forest fragment. In: Primates in Fragments. Complexity and Resilience (eds. L. Marsh and C. Chapman), pp. 447-456. New York: Springer.

Beldomenico PM, Begon M. 2010. Disease spread, susceptibility and infection intensity: vicious circles? Trends in Ecology \& Evolution 25, 21-27.

Beldomenico PM, Telfer S, Gebert S, Lukomski L, Bennett M, Begon M. 2008a. Poor condition and infection: a vicious circle in natural populations. Proceedings of the Royal Society B: Biological Sciences 275, 1753-1759.

Beldomenico PM, Telfer S, Gebert S, Lukomski L, Bennett M, Begon M. 2008b. The dynamics of health of wild field vole (Microtus agrestis) populations: a haematological perspective. Journal of Animal Ecology 77, 984-997.

Beldomenico PM, Telfer S, Gebert S, Lukomski L, Bennett M, Begon M. 2009a. The vicious circle and infection intensity: the case of Trypanosoma microti in field vole populations. Epidemics 1, 162-167

Beldomenico PM, Telfer S, Gebert S, Lukomski L, Bennett M, Begon M. 2009b. Host condition and individual risk of cowpox virus infection: cause or effect? Epidemiology \& Infection 137, 1295-1301.

Belthoff JR, Dufty jr AM. 1998. Corticosterone, body condition and locomotor activity: a model for dispersal in screechowls. Animal Behaviour 55, 405-415. 
Blanchet S, Thomas F, Loot G. 2009. Reciprocal effects between host phenotype and pathogens: new insights from an old problem. Trends in Parasitology 25, 364-369.

Boonstra R. 2013. Reality as the leading cause of stress: rethinking the impact of chronic stress in nature. Functional Ecology 27, 11-23.

Boonstra R, McColl C. 2000. Contrasting stress response of male arctic ground squirrels and red squirrels. Journal of Experimental Zoology 286, 390-404.

Boonstra R, McColl C, Karels T. 2001. Reproduction at all costs: the adaptive stress response of male arctic ground squirrels. Ecology 82, 1930-1946.

Brown M, Schmid-Hempel R, Schmid-Hempel P. 2003. Strong context-dependent virulence in a host-parasite system: reconciling genetic evidence with theory. Journal of Animal Ecology 72, 994-1002.

Brown T, Fuller C. 2006. Stress and paras itism in whitefooted mice (Peromyscus leucopus) in dry and floodplain environments. Canadian Journal of Zoology 84, 18331839.

Carruth L, Jones R, Norris D. 2014. Cortisol and Pacific salmon: a new look at the role of stress hormones in olfaction and home-stream migration. Inte-grative and Comparative Biology 42, 574-581.

Chapman CA, Wasserman MD, Gillespie TR, Speirs ML, Lawes MJ, Saj TL, Ziegler TE. 2006a. Do food availability, parasitism, and stress have synergistic effects on red colobus populations living in forest fragments? American Journal of Physical Anthro-pology 131, 525-534.

Chapman C, Wasserman M, Gillespie T. 2006b. Behavioural patterns of colobus in logged and unlogged forests: the conservation value of harvested forests. In: Primates of Western Uganda (eds. E. Newton-Fisher, H. Notman, V. Reynolds and J. Patterson), pp. 373-390. New York: Springer.

Coors A, De Meester L. 2008. Synergistic, antagonistic and additive effects of multiple stressors: predation threat, parasitism and pesticide exposure in Daphnia magna. Journal of Applied Ecology 45, 1820-1828.

Coors A, Decaestecker E, Jansen M, De Meester L. 2008. Pesticide exposure strongly enhances parasite virulence in an invertebrate host model. Oikos 117, 1840-1846.

Coulson T, Catchpole EA, Albon SD, Morgan BJ, Pemberton JM, Clutton-Brock TH, Crawley MJ, Grenfell BT. 2001. Age, sex, density, winter weather, and population crashes in Soay sheep. Science 292, 1528-1531.

Creel S, Dantzer B, Goymann W, Rubenstein D. 2013. The ecology of stress: effects of the social environment. Functional Ecology 27, 66-80.

Crossin G, Trathan P, Phillips R, Gorman K, Dawson A, Sakamoto K, Williams T. 2012. Corticosterone predicts foraging behavior and parental Care in Macaroni Penguins. American Naturalist 180, E31-E41.
Di Rosa I, Simoncelli F, Fagotti A, Pascolini R. 2007. Ecology: the proximate cause of frog declines? Nature 447, E4-E5.

Du, S.Y., Cao, Y.F., Nie, X.H., Wu, Y., Bian, J.H. (2015). The synergistic effect of density stress during the maternal period and adulthood on immune traits of root vole (Microtus oeconomus) individuals-a field experiment. Oecologia DOI 10.1007/s00442-015-3445-9.

Eberhardt A, Costa S, Marini R, Racca A, Baldi C, Robles R, Moreno P, Beldomenico P. 2013. Parasite load and physiological trade-offs in stressed capybaras. PLoS One 8, e70382.

El-Lethey H, Huber-Eicher B, Jungi TW. 2003. Exploration of stress-induced immunosuppression in chickens reveals both stress-resistant and stress-susceptible antigen responses. Veterinary Immuno-logy and Immunopathology 95, 91-101.

Fink G. 2009. Stress: definition and history. In Encyclopedia of Neuroscience (ed. L. Squire), pp. 549-555. Oxford: Elsevier Ltd.

Forbes KM, Henttonen H, Hirvelä-Koski V, Kipar A, Mappes T, Stuart $P$, Huitu O. 2015. Food provisioning alters infection dynamics in populations of a wild rodent. Proceedings of the Royal Society B 282, 20151939.

Franceschini MD, Custer CM, Custer TW, Reed JM, Romero LM. 2008. Corticosterone stress response in tree swallows nesting near polychlorinated biphenyl- and dioxin-contaminated rivers. Environmental Toxicology and Chemestry 27, 2326-2331.

Gabor CR, Fisher MC, Bosch J. 2013. A non-invasive stress assay shows that tadpole populations infected with Batrachochytrium dendrobatidis have elevated corticosterone levels. PLoS One 8, e56054.

Garner T, Walker S, Bosch J, Leech S, Rowcliffe J, Cunningham AA, Fisher M. 2009. Life history tradeoffs influence mortality associated with the amphibian pathogen Batrachochytrium dendro-batidis. Oikos 118, 783-791.

Gervasi S, Foufopoulos J. 2008. Costs of plasticity: responses to desiccation decrease post-meta-morphic immune function in a pond-breeding amphibian. Functional Ecology 22, 100-108

Giles N. 2006. Predation risk and reduced foraging activity in fish: experiments with parasitized and non-parasitized three-spined sticklebacks, Gaste-rosteus aculeatus L. Journal of Fish Biology 31, 37-44.

Gillespie T, Chapman C, Greiner E. 2005. Effects of logging on gastrointestinal parasite infections and infection risk in African primates. Journal of Applied Ecology 42, 699-707.

Gordon G, Brown A, Pulsford T. 1988. A koala (Phascolarctos cinereus Goldfuss) population crash during drought and heatwave conditions in south-western Queensland. Austral Ecology 13, 451-461.

Govic A, Levay EA, Kent S, Paolini AG. 2009. The social behavior of male rats administered an adult-onset calorie restriction regimen. Physiology \& Behavior 96, 581-585. 
Grenfell BT, Wilson K, Isham VS, Boyd HE, Dietz K. 1995. Modelling patterns of parasite aggregation in natural populations: trichostrongylid nematode-ruminant interactions as a case study. Parasitology 111 Suppl, S135-S151.

Grissom N, Bhatnagar S. 2009. Habituation to repeated stress: get used to it. Neurobiology of Learning and Memory 92, 215-224.

Gulland FM. 1992. The role of nematode parasites in Soay sheep (Ovis aries L.) mortality during a population crash. Parasitology 105, 493-503.

Gulland FM, Albon SD, Pemberton JM, Moorcroft PR, CluttonBrock TH. 1993. Parasite-associated polymorphism in a cyclic ungulate population. Proceedings of the Royal Society B: Bioligical Sciences 254, 7-13.

Hayward AD, Wilson AJ, Pilkington JG, Pemberton JM, Kruuk LE. 2009. Ageing in a variable habitat: environmental stress affects senescence in parasite resistance in St Kilda Soay sheep. Proceedings of the Royal Society B: Bioligical Sciences 276, 3477-3485.

Howard R. 1980. Mating behavior and mating success in wood frogs, Rana sylvatica. Animal Behaviour 28, 705716.

Huitu O, Jokinen I, Korpimäki E, Koskela E, Mappes T. 2007. Phase dependence in winter physiological condition of cyclic voles. Oikos 116, 565-577.

Kelly DF, Poulin R, Tompkins D, Townsend C. 2010. Synergistic effects of glyphosate formulation and parasite infection on fish malformations and survival. Journal of Applied Ecology 47, 498-504.

Kiesecker J. 2010. Global stressors and the global decline of amphibians: tipping the stress immunocompetency axis. Ecological Research 26, 897-908.

Koolhaas JM. 2008. Coping style and immunity in animals: making sense of individual variation. Brain Behavior \& Immunity 22, 662-667.

Koolhaas JM, Bartolomucci A, Buwalda B, de Boer SF, Flugge G, Korte SM, Meerlo P, Murison R, Olivier B, Palanza P et al. 2011. Stress revisited: a critical evaluation of the stress concept. Neuroscience \& Biobehavioral Reviews $35,1291-1301$.

Koolhaas JM, Korte SM, de Boer SF, Van Der Vegt BJ, Van Reenen CG, Hopster H, De Jong IC, Ruis MA, Blokhuis HJ. 1999. Coping styles in animals: current status in behavior and stress-physiology. Neuro-science \& Biobehavioral Reviews 23, 925-935.

Korte SM, Koolhaas JM, Wingfield JC, McEwen BS. 2005. The Darwinian concept of stress: benefits of allostasis and costs of allostatic load and the trade-offs in health and disease. Neuroscence \& Biobehavioral Reviews 29, 3-38.

Krebs C, Boonstra R. (1978). Demography of the spring decline in populations of the vole, Microtus townsendii. Journal of Animal Ecology 47, 1007-1015.
Lafferty KD, Shaw JC. 2013. Comparing mechanisms of host manipulation across host and parasite taxa. Journal of Experimental Biology 216, 56-66.

Lange B, Reuter M, Ebert D, Muylaert K, Decaestecker E. 2014. Diet quality determines interspecific parasite interactions in host populations. Ecology and Evolution 4, 3093-3102.

Laurance WF, Useche DC, Rendeiro J, Kalka M, Bradshaw CJ, Sloan SP, Laurance SG, Campbell M, Abernethy K, Alvarez $P$ et al. 2012. Averting biodiversity collapse in tropical forest protected areas. Nature 489, 290-294.

Laws S C, Hotchkiss M, Ferrell J, Jayaraman S, Mills L, Modic W, Tinfo N, Fraites M, Stoker T, Cooper R. 2009. Chlorotriazine herbicides and metabolites activate an ACTH-dependent release of corticosterone in male Wistar rats. Toxicological Sciences 112, 78-87.

Leggett HC, Buckling A, Long GH, Boots M. 2013. Generalism and the evolution of parasite virulence. Trends in Ecology \& Evolution 28, 592-596.

Levine S, Ursin H. 1991. What is stress? In: Stress: Neurobiology and Neuroendocrinology (eds. M. Brown, G. Koob and C. Rivier), pp. 3-21. New York: Marcel Dekker Inc.

Lochmiller RL. 1996. Immunocompetence and animal population regulation. Oikos 76, 594-602.

Lotters S, Kielgast J, Bielby J, Schmidtlein S, Bosch J, Veith M, Walker SF, Fisher MC, Rodder D. 2009. The link between rapid enigmatic amphibian decline and the globally emerging chytrid fungus. Ecohealth 6, 358-372.

Manzoli DE, Antoniazzi LR, Saravia MJ, Silvestri L, Rorhmann D, Beldomenico PM. 2013. Multi-level determinants of parasitic fly infection in forest passerines. PLoS One 8, e67104.

Marcogliese DJ, Pietrock M. 2011. Combined effects of parasites and contaminants on animal health: parasites do matter. Trends in Parasitology 27, 123-130.

Martin LB, Ghalambor C, Woods A. 2015. Integrative Organismal Biology. Hoboken, NJ, USA: John Wiley \& Sons, Inc.

Martin LB. 2009. Stress and immunity in wild vertebrates: Timing is everything. General and Comparative Endocrinology 163, 70-76.

Martin L, Gilliam J, Han P, Lee K, Wikelski M. 2005. Corticosterone suppresses cutaneous immune function in temperate but not tropical house sparrows, Passer domesticus. General and Comparative Endocrinology 140, 126-135.

Martin L, Navara K, Bailey M, Hutch C, Powell N, Sheridan J, Nelson R. 2008. Food Restriction Compromises Immune Memory in Deer Mice (Peromyscus maniculatus) by Reducing Spleen-Derived Antibody-Producing B Cell Numbers. Physiological and Biochemical Zoology 81, 366372. 
McEwen BS. 1998. Stress, adaptation, and disease. Allostasis and allostatic load. Annals of the New York Academy of Sciences 840, 33-44.

McEwen BS. 2002. Protective and damaging effects of stress mediators: the good and bad sides of the response to stress. Metabolism 51, 2-4.

McEwen BS, Wingfield JC. 2003. The concept of allostasis in biology and biomedicine. Hormones \& Behavior 43, 2-15.

McNamara J, Buchanan K. 2005. Stress, resource allocation, and mortality. Behavioural Ecology 16, 1008-1017.

Moreira J, Ferraz K, Herrera E, McDonald D. 2013. Capybara: Biology, Use and Conservation of an Exceptional Neotropical Species. Verlag: Springer.

Munck A, Guyre PM, Holbrook NJ. 1984. Physiological functions of glucocorticoids in stress and their relation to pharmacological actions. Endocrine Reviews 5, 25-44.

Nazzi F, Brown SP, Anno scia D, Del PF, Di PG, Varricchio P, Della VG, Cattonaro F, Caprio E, Pennacchio F. 2012. Synergistic parasite-pathogen interactions mediated by host immunity can drive the collapse of honeybee colonies. PLoS Pathogens 8, e1002735.

Nussey DH, Watt KA, Clark A, Pilkington JG, Pemberton JM, Graham AL, McNeilly TN. 2014. Multivariate immune defences and fitness in the wild: complex but ecologically important associations among plasma antibodies, health and survival. Proceedings of the Royal Society $B$ : Biological Sciences 281, 20132931

Ould P, Welch H. 1980. The effect of stress on the parasitism of mallard ducklings by Echinuria uncinata (Nematoda: Spirurida). Canadian Journal of Zoology 58, 228-234.

Pacak K, Palkovits M. 2001. Stressor specificity of central neuroendocrine responses: implications for stressrelated disorders. Endocrine Reviews 22, 502-548.

Parmesan C, Burrows MT, Duarte CM, Poloczanska ES, Richardson AJ, Schoeman DS, Singer MC. 2013. Beyond climate change attribution in conservation and ecological research. Ecology Letters 16, 58-71.

Pedersen AB, Greives TJ. 2008. The interaction of parasites and resources cause crashes in a wild mouse population. Journal of Animal Ecology 77, 370-377.

Peterson JD, Steffen JE, Reinert LK, Cobine PA, Appel A, Rollins-Smith L, Mendonca MT. 2013. Host stress response is important for the pathogenesis of the deadly amphibian disease, Chytridiomycosis, in Litoria caerulea. PLoS One 8, e62146.

Plowright RK, Eby P, Hudson PJ, Smith IL, Westcott D, Bryden WL, Middleton D, Reid PA, McFarlane RA, Martin G et al. 2015. Ecological dynamics of emerging bat virus spillover. Proceedings of the Royal Society B: Biological Sciences 282: 20142124.

Plowright RK, Field HE, Smith C, Divljan A, Palmer C, Tabor G, Daszak P, Foley JE. 2008. Reproduction and nutritional stress are risk factors for Hendra virus infection in little red flying foxes (Pteropus scapulatus). Proceedings of the Royal Society B: Biological Sciences 275, 861-869.

Raberg L, Grahn M, Hasselquist D, Svensson E. 1998. On the adaptive significance of stress-induced immunosuppression. Proceedings of the Royal Society B: Biological Sciences 265, 1637-1641.

Raouf S, Smith L, Bomberger-Brown M, Wingfield JC, Brown C. 2006. Glucocorticoid hormone levels increase with group size and parasite load in cliff swallows. Animal Behaviour 71, 39-48.

Rausch RL, George JC, Brower HK. 2007. Effect of climatic warming on the Pacific walrus, and potential modification of its helminth fauna. Journal of Parasitology 93, 1247-1251.

Reading CJ. 2007. Linking global warming to amphibian declines through its effects on female body condition and survivorship. Oecologia. 151, 125-131.

Reeder D, Kramer K. 2005. Stress in free-ranging mammals: integrating physiology, ecology, and natural history. Journal of Mammalogy 86, 225-235.

Relyea RA. 2004. Synergistic impacts of malathion and predatory stress on six species of North American tadpoles. Environmental Toxicology and Chemistry 23, 1080-1084.

Riascos J, Heilmayer O, Oliva M, Laudien J. 2011. Environmental stress and parasitism as drivers of population dynamics of Mesodesma donacium at its northern biogeographic range. ICES Journal of Marine Science 68, 823-833.

Sapolsky R, Romero L, Munck A. 2000. How do glucocorticoids influence stress responses? Integrating permissive, suppressive, stimulatory, and preparative actions. Endocrine Reviews 21, 55-89.

Selye H. 1936. A syndrome produced by diverse nocuous agents. Nature 138, 32.

Selye H. 1975. Confusion and controversy in the stress field. Journal of Human Stress 1, 37-44.

Smith D. 1987. Adult recruitment in chorus frogs - effects of size and date at metamorphosis. Ecology 68, 344-350.

St Juliana J, Khokhlova I, Wielebnowski N, Kotler B, Krasnov B. 2014. Ectoparasitism and stress hormones: strategy of host exploitation, common host-parasite history, and energetics matter. Journal of Animal Ecology 83, 11131123

Sures B, Knopf K, Kloas W. 2001. Induction of stress by the swimbladder nematode Anguillicola crassus in European eels, Anguilla anguilla, after repeated experimental infection. Parasitology 123, 179-184.

Sykes A. 1987. Endoparasites and herbivore nutrition. In Nutrition of Herbivores (eds. J. Hacker and J. Ternouth), pp. 211-232. Harickvale: Academic Press Australia.

Tempel DL, Leibowitz SF. 1994. Adrenal steroid receptors: interactions with brain neuropeptide systems in relation 
to nutrient intake and metabolism. Journal of Neuroendocrinology 6, 479-501.

Thomas F, Brown SP, Sukhdeo M, Renaud F. 2002. Understanding parasite strategies: a state-dependent approach? Trends in Parasitology 18, 387-390.

Turnbull A, Rivier C. 1999. Regulation of the hypothalamicpituitary-adrenal axis by cytokines: actions and mechanisms of action. Phisiological Reviews 79, 1-71.

Utaaker K, Robertson L. 2015. Climate change and foodborne transmission of parasites: A consideration of possible interactions and impacts for selected parasites. Food Research International 68, 16-23.

Vestey MR, McMurry ST, Lochmiller RL. 1993. Influence of dietary protein on selected measures of humoral and cellular immunity in the cotton rat, Sigmodon hispidus. Canadian Journal of Zoology 71, 579-586.

Wingfield J. 2013a. Ecological processes and the ecology of stress: the impacts of abiotic environmental factors. Functional Ecology 27, 37-44.

Wingfield J. 2013b. The comparative biology of environmental stress: behavioural endocrinology and variation in ability to cope with novel, changing environments. Animal Behaviour 85, 1127-1133.

Wolinska J, King KC. 2009. Environment can alter selection in host-parasite interactions. Trends in Parasitology 25, 236-244.

Yang S, Ruuhola T, Rantala M. 2007. Impact of starvation on immune defense and other life-history traits of a $n$ outbreaking geometrid, Epirrita autumnata: a possible causal trigger for the crash phase of population cycle. Annales Zoologici Fennici 44, 89-96. 